In accordance with this Journal's policies the reports listed below are published only on the Internet site of this Journal.

The full text and figures may be accessed at no cost at: www.karger.com/cgr.

Cytogenet Genome Res 101:A1-A2 (2003)

DOI: $10.1159 / 000074176$

Assignment of the $\beta-\mathrm{N}$-acetylhexosaminidase gene (HEXB) to porcine chromosome SSC2q21 $\rightarrow$ q22 by fluorescence in situ hybridization and by analysis of somatic cell and radiation hybrid panels

A. Mueller, ${ }^{a}$ C. Knorr, ${ }^{a}$ F. Habermann, ${ }^{b}$ K. Slanchev, ${ }^{a}$

D. Zwilling, ${ }^{a}$ R. Fries ${ }^{b}$ and B. Breniga

${ }^{a}$ Institute of Veterinary Medicine, Georg August University of Göttingen, Göttingen (Germany)

${ }^{\mathrm{b}}$ Chair of Animal Breeding and Molecular Genetics, Technical

University of Munich, Munich (Germany)

Cytogenet Genome Res 101:B1-B2 (2003)

DOI: $10.1159 / 000074177$

\section{Assignment of the sperm protein zona receptor tyrosine kinase gene (SPRMTK) to porcine chromosome SSC3q11 $\rightarrow$ q12 by fluorescence in situ hybridization and by analysis of somatic cell and radiation hybrid panels \\ L. Bull, a S. Jansen, ${ }^{a}$ F. Habermann, ${ }^{b}$ R. Fries, ${ }^{b}$ C. Knorra and \\ B. Breniga \\ a Institute of Veterinary Medicine, Georg-August-University of Göttingen, Göttingen (Germany); \\ ${ }^{\mathrm{b}}$ Chair of Animal Breeding and Molecular Genetics, Technical \\ University of Munich, Munich (Germany)}

Cytogenet Genome Res 101:C1-C4 (2003)

DOI: $10.1159 / 000074178$

\section{Assignment of SOD3 to human chromosome band $4 p 15.3 \rightarrow$ p15.1 with somatic cell and radiation hybrid mapping, linkage mapping, and fluorescent in-situ hybridization}

L.F. Stern, a N.H. Chapman, b.M. Wijsman, b,c M.R. Altherr ${ }^{d}$ and D.R. Rosen ${ }^{a}$

a Division of Molecular Medicine, Wadsworth Center, New York State Department of Health, Albany, NY; b Department of Biostatistics, and ${ }^{c}$ Division of Medical Genetics, Department of Medicine, University of Washington, Seattle, WA; ${ }^{\mathrm{d}}$ Genomics Group, Los Alamos National Laboratory, Los Alamos, NM (USA)
Cytogenet Genome Res 101:D1-D2 (2003)

DOI: $10.1159 / 000074179$

Assignment of DNA cytosine-5methyltransferase 1 (DNMT1) gene to porcine chromosome 2 q21 $\rightarrow$ q22 by somatic cell and radiation hybrid panel mapping

N. Bosak, ${ }^{a}$ S. Fujisaki, ${ }^{a}$ S. Kiuchi, ${ }^{a}$ H. Hiraiwa ${ }^{b}$ and H. Yasue ${ }^{a}$

${ }^{a}$ Genome Research Department, National Institute of Agrobiological Sciences, Tsukuba;

b New Energy and Industrial Technology Developmental Organization, Toshima, Tokyo (Japan)

Cytogenet Genome Res Res 101:E1-E2 (2003) DOI: $10.1159 / 000074180$

Assignment of the gene (MBD3) encoding methyl-CpG binding domain protein 3 to porcine chromosome $2 q 21 \rightarrow q 22$ by somatic cell and radiation hybrid panel mapping

N. Bosak, a S. Fujisaki, ${ }^{a}$ S. Kiuchi, ${ }^{a}$ H. Hiraiwa ${ }^{b}$ and H. Yasue ${ }^{a}$ ${ }^{a}$ Genome Research Department, National Institute of Agrobiological Sciences, Tsukuba;

${ }^{b}$ New Energy and Industrial Technology Developmental Organization, Toshima, Tokyo (Japan)

Cytogenet Genome Res 101:F1-F3 (2003) DOI: 10.1159/000074181

\section{Assignment of the porcine} hyaluronidase-3 (HYAL3) gene to SSC13q21 by FISH and confirmation by hybrid panel analyses

K. Gatphayak, ${ }^{\text {a C. Knorr, }}{ }^{\text {a F. Habermann, }}{ }^{\mathrm{b}}$ R. Fries ${ }^{\mathrm{b}}$ and B. Breniga

a Institute of Veterinary Medicine, Georg-August-University of Göttingen, Göttingen;

${ }^{b}$ Institute of Animal Breeding and Molecular Genetics, Technical University of Munich, Munich (Germany) 